\title{
Effect Of Windscreen Glass Waste Powder (WGWP) Mortar On Water Absorption
}

\author{
Nik Anisah Nik Ngah ${ }^{1}$, Maziah Muda ${ }^{1}$, Ahmad Nasrul Hisyam Hamzah ${ }^{2}$, Mohamad Awang ${ }^{3}$, \\ Kartini Kamaruddin ${ }^{4}$ \\ ${ }^{1}$ Kolej Komuniti Kuala Terengganu, Jalan Tengku Ampuan Mariam, \\ 20200 Kuala Terengganu, Terengganu Darul Iman, Malaysia. \\ ${ }^{2}$ Kolej Komuniti Kok Lanas, 16450 Ketereh, Kelantan Darul Naim, Malaysia \\ ${ }^{3}$ School of Ocean Engineering, Universiti Malaysia Terengganu, \\ 21030 Kuala Terengganu, Terengganu Darul Iman, Malaysia. \\ ${ }^{4}$ Faculty of Civil Engineering, Universiti Teknologi Mara, \\ 40450 Shah Alam, Selangor Darul Ehsan, Malaysia.
}

\begin{abstract}
Diverting waste material from landfill sites has a big implication for the creation of new markets and has environmental benefits through offsetting the need for the extraction of raw materials. Besides, the major attention especially in construction industry is the problem to make natural resources sustainable for three to four decades in future. However, in this study finely glass powder with pozzolanic properties is found to be a partial replacement for cement and can acts as filler in the microstructure of a mortar block. Thus, a study was conducted to see the effects of various proportions of windscreen glass waste powder (WGWP) in determining the degree of water absorption on mortar incorporated with WGWP and to determine the optimum replacement to the ordinary Portland cement (OPC) with WGWP. Several compositions of WGWP $(0 \%, 5 \%, 10 \%, 15 \%$ and $20 \%$ by cement weight) of mortar cube sample were prepared and cured at 7, 28 and 60 days to undergo a water absorption test. From this research, it shows that the use of WGWP was found to be the best features pozzolanic enough to use as a partial replacement for cement and it can reduced the pores of mortar by blocking the large voids in the hydrated cement paste through pozzolanic reaction. In the term of water absorption, the lowest reading was achieved in $15 \%$ and it can be said that $15 \%$ replacement is the optimum replacement of OPC.
\end{abstract}

Key words: cement replacement, windscreen glass waste powder, pozzolanic, absorption.

\section{INTRODUCTION}

Malaysia is one of a country that is blessed with enormous in natural resources. One of the valuable natural resource is limestone, where it contributes in a big role of producing cement for construction needs. Besides, the concrete demand is increasing day by day and it is the most widely used man made in construction material. Only recently, the Malaysian public especially in industrial main cement supplier, these sources are finite and the need for recycling the natural resources has become a main issue in order to make concrete industry sustainable.

Apart from that, according to generation of Malaysia Municipal Solid Waste (MSW), solid waste has increased more than $91 \%$ over the last decade and wastes are endlessly turned into a main environment issue in Malaysia. A report showed that, the highest average waste generation rate per capita of MSW is in Penang, with $1.1 \mathrm{~kg} / \mathrm{capita} / \mathrm{day}$ which are enough to fill up 42 buildings. Thus, since the industrial revolution is keep expanding, some actions have to be taken to overcome this problem.

Among various urban solid waste, glass may be considered the most suitable s ubstitution for sand and cement due to its physical characteristis and chemical compositions [1, 2, 3, 4]. Schwarz et. al, [5] reported that the durability of concrete has the potential to be improved when the fine glass powder passing $45 \mu \mathrm{m}$. There are many types of waste that are non-recyclable 
and recyclable wastes. A main consumer of natural resources and a significant waste generator is coming from construction industry.[6]. However, the reuse of waste generated into constructions materials can solve to minimize these environment impacts.

Several studies were carried out using waste glass incorporated into concrete and mortar as a partial substitute for construction material in attempt to take the advantage of the pozzolanic properties of the material [7,8]. Studies carried by Kartini et. al, [9] showed that the benefit of including cement replacement materials significantly improves the durability properties of concrete due to its reduced pores. Besides, based on the studies conducted by Calmon et. al . [6] have examined about the pozzolanic behaviour of glass residue, and they also found that particle grain size has a great relationship between the waste pozzolanic behaviour. They concluded greater grain size showed small pozzolanic activity, while for smaller grain size, the pozzolanic characteristics were increased. Therefore, it can be confirmed that the particle size of the grain does have a greater effect on the pozzolanic index [7].

In addition, the using of the portlandite, calcium hydroxide $\mathrm{Ca}(\mathrm{OH})_{2}$, the pozzolanic reaction reduces the formation of gypsum, densification of pore structure thus reducing the permeability because the formation of secondary $\mathrm{C}-\mathrm{S}-\mathrm{H}$ and thirdly, reduction of tricalcium aluminate $\mathrm{C}_{3} \mathrm{~A}$ content can reduce the aluminate bearing phases [8]. Moreover, by consuming the waste material such as windscreen glass can reduce the amount of dumped waste also can reduce the emission of carbon dioxide $\left(\mathrm{CO}_{2}\right)$ to the atmosphere [10].

The objective of this study on windscreen glass waste powder (WGWP) is to determine its suitability as cement replacement material. The physical, chemical and water absorption of mortar with different compositions of WGWP cement to sand $(\mathrm{C}: \mathrm{S})$ ratios were investigated.
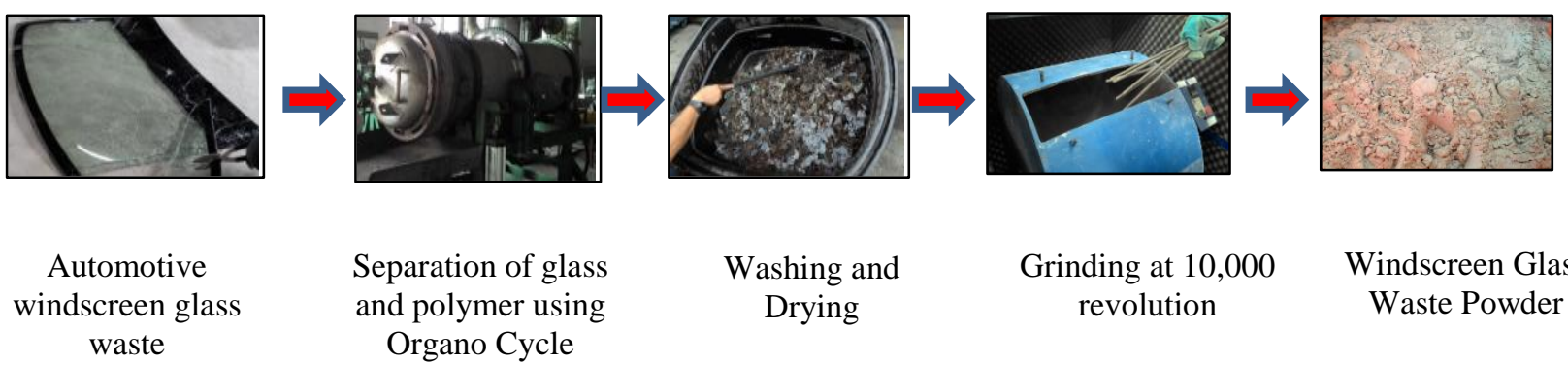

$$
\begin{aligned}
& \text { Separation of glass } \\
& \text { and polymer using } \\
& \text { Organo Cycle }
\end{aligned}
$$

\section{EXPERIMENT}

The test of fineness of OPC and WGWP using the nitrogen absorption method and Brunauer, Emmatt and Teller (BET) equipment was conducted to determine the specific surface area. The density identified by Gas Pycnometry- Micromeritics 1340. The particle size distribution was determined using Mastersizer 2000 Laser Particle Size Analyzer. Scanning Electron Microscope (SEM) model JM6100 to find out the particle morphology of the sample of OPC and WGWP. The Energy Dispersing X-ray Spectroscopy (EDAX) and X-ray Diffraction (XRD) analyzer were used in order to determine the content element of WGWP.

The automotive windscreen glass waste was obtained from nearby workshops in Terengganu, Malaysia. The process involved the removing of the gluing polymer from the glass using Organo Cycler machine at Mariwealth Engineering \& Consultancy Sdn. Bhd, Selangor. The Los Angeles machine was used to grind windscreen glass up to 10,000 revolutions to produce the automotive windscreen glass waste powder (WGWP). Fig. 1 shows the flow of the preparation of WGWP. Supplementary materials used in the mortar were Ordinary Portland Cement (OPC) and fine aggregate of $5 \mathrm{~mm}$ maximum size.

\section{Testing}

This study was carried out by preparing 60 numbers of mortar cube specimens with dimensions of $50 \mathrm{~mm} \mathrm{x}$ $50 \mathrm{~mm}$ x 50mm. Five mix proportions were adopted comprising various percentages of WGWP $(0 \%, 5 \%$, $10 \%, 15 \%$ and $20 \%$ ) by weight of cement, whilst employing cement to sand $(\mathrm{C}: \mathrm{S})$ ratio of $1: 3.0$. The water to cement $(\mathrm{w} / \mathrm{c})$ ratio was fixed at 0.5 . The mortar cube specimens were cured in the water to the water absorption test at 7,28 and 60 days. For mix compositions of 1:3.0, the cement contents was $2.08 \mathrm{~kg}$. The sand contents were $6.93 \mathrm{~kg}$. The water absorption test was conducted in compliance to ASTM 1403-13 [11].

Fig 1 Preparation of automotive windscreen glass waste powder (WGWP) 


\section{RESULT AND DISCUSSION}

Table 1 shows the result of BET surface area and total area in pores for both OPC and WGWP. It shows that WGWP has smaller surface area as compared to that of OPC. Practically, surface area is closely related to the particle size where they are inversely proportional. The specific surface area increases as the particle size becomes small. In this research, WGWP also has higher total area in pores compared to OPC. Therefore the density of WGWP is lower than OPC. Surface area is important in determining workability, water absorption and the durability of concrete. The surface of a material is the dividing line between a solid and its surroundings, liquid, gas or another solid. Surface area affects cement hydrates, adsorption capacity of air and water purifiers, and the processing of most powders and porous materials. Whenever solid matter becomes smaller particles new surfaces are created thereby increasing the surface area.

Table 1 Surface area and total area in pores of OPC and WGWP

\begin{tabular}{|l|c|c|}
\hline Parameter/Material & OPC & WGWP \\
\hline BET Surface Area $\left(\mathrm{m}^{2} / \mathrm{g}\right)$ & 1.0242 & 0.6462 \\
\hline Total area in pores $\left(\mathrm{m}^{2} / \mathrm{g}\right)$ & 0.1250 & 0.2100 \\
\hline Density $\left(\mathrm{g} / \mathrm{cm}^{3}\right)$ & 2.9885 & 2.5318 \\
\hline
\end{tabular}

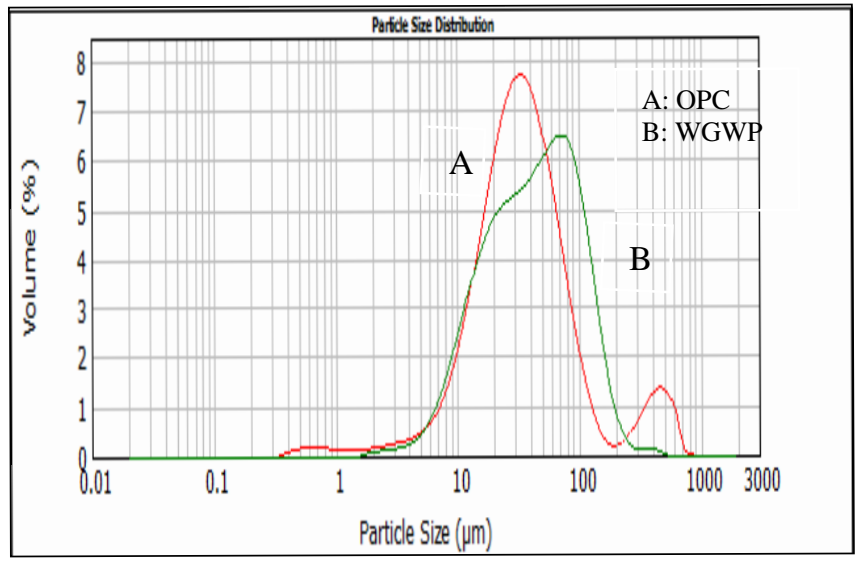

Fig 2 Particles size distributions of OPC and WGWP

Table 2 Chemical compositions of raw materials

\begin{tabular}{|l|c|c|c|c|c|c|c|}
\hline \multirow{2}{*}{ Material } & \multicolumn{7}{|c|}{ Chemical compositions (\%) } \\
\cline { 2 - 8 } & $\mathrm{SiO}_{2}$ & $\mathrm{CaO}$ & $\mathrm{Al}_{2} \mathrm{O}_{3}$ & $\mathrm{Fe}_{2} \mathrm{O}_{3}$ & $\mathrm{Na}_{2} \mathrm{O}$ & $\mathrm{MgO}$ & $\mathrm{K}_{2} \mathrm{O}$ \\
\hline OPC & 16.03 & 69.06 & 4.14 & 5.09 & 0.02 & 0.67 & 1.3 \\
\hline WGWP & 76.11 & 5.01 & 3.45 & 0.38 & 10.10 & 4.00 & 0.33 \\
\hline
\end{tabular}

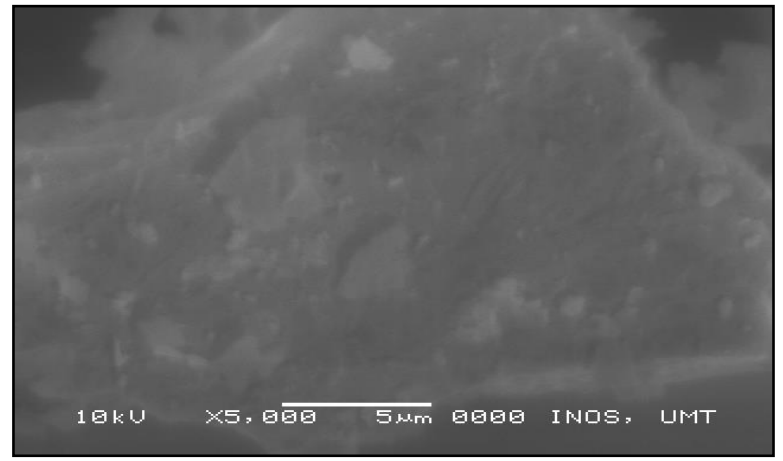

(a) OPC particles $-5,000 \mathrm{x}$ magnification

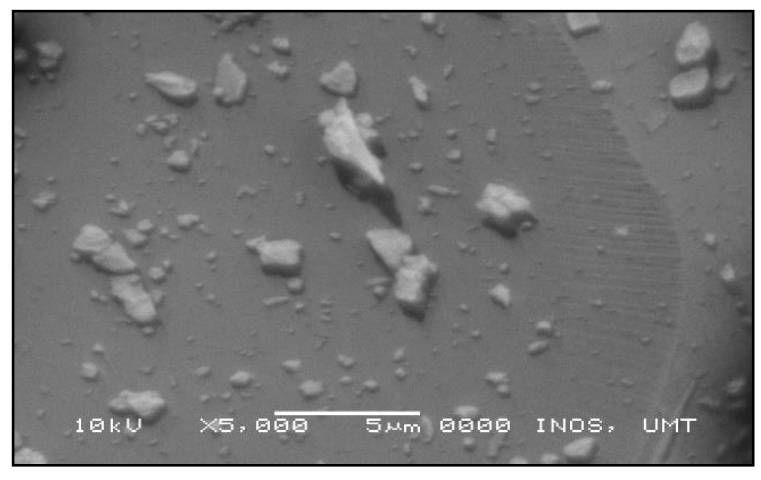

(b) WGWP particles - 5,000x magnification

Fig 3 SEM of OPC and WGWP particles

Fig. 2 shows the particle size distribution of OPC and WGWP. The WGWP was expected to serve as a filler and also a supplementary cementitious material with pozzolanic activity $[12,13,14]$. Fig. 3 (a) and (b), showed the particle morphology of OPC and WGWP respectively which was obtained by using Scanning Electron Microscopy (SEM). The particles of WGWP had angular and crushed shapes.

From Table 2, shows the chemical composition of OPC and WGWP with the calcium oxide $(\mathrm{CaO})$ content for OPC was about $69.06 \%$, while the silicon dioxide $\left(\mathrm{SiO}_{2}\right)$ of WGWP was about $76.11 \%$. The chemical compositions of raw materials was determined using Energy Dispersing X-ray Spectroscopy (EDAX). Therefore, this finding is in agreement with ASTM C618-02 [15]. which requires a sum of $\mathrm{SiO}_{2}+\mathrm{AI}_{2} \mathrm{O}_{3}+$ $\mathrm{Fe}_{2} \mathrm{O}_{3}$ higher than $70 \%$ for good pozzolan, and in this study a total of $79.94 \%$ is obtained for WGWP.

The studied glass sample presents satisfactory chemical composition. It classified the Class $\mathrm{N}$ natural pozzolan and therefore, it is likely to produce a good pozzolan. 
However, to predict the pozzolanic activity, the chemical compositions should not be used as the only criterion. It is because the amorphous state is also required and it has been confirmed for WGWP using $\mathrm{XRD}$ analyzer as shown in Fig. 4. Indeed, no peaks attributed to any crystallized compound can be identified except a broad diffraction halo, which is attributed to the glassy phase. Fig. 4 shows the XRD of WGWP particles. The XRD of WGWP shown in Fig. 4 indicates that the structure of silica present in WGWP used in the present study is of amorphous material with a diffused peak of 120 counts at about $\theta=20^{\circ}$.

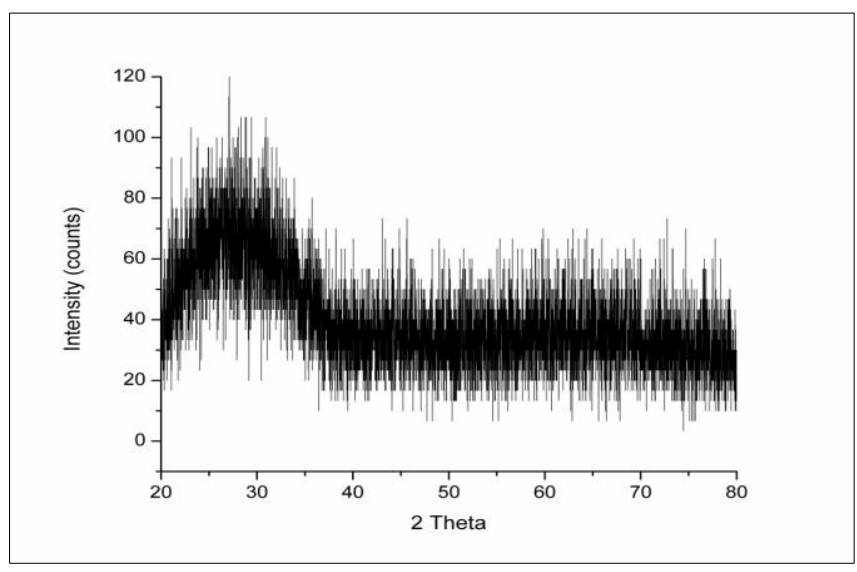

Fig 4 X-ray diffraction of WGWP

The water absorption rate at 7,28 and 60 days of curing result was summarised as shown in Figure 5. Based on the water absorption test conducted on three different curing days, it can be seen that, curing period of 60 days represent the lowest reading compared to 7 days and 28 days. This is might be extending the curing period can reduce the permeability, and this is in line with the research conducted by Nassar \& Soroushian [4].

Thus, the permeability in 60 days of curing showed the lowest reading among the others because the length of curing period is longer, thus gives a significant impact to the decreasing in permeability.

Apart of that, 15\% of WGWP replacement shows the lowest reading among the other four mixes. This is because, in this $15 \%$ replacement the water absorption and the porosity of mortar block with glass powder to be the optimum level as partial cement alternatives. Besides, it has been shown that it can acts as filler and may have sufficient pozzolonic properties over time in hours. Moreover, the replacement was found to have a correlation with the permeability of mortar [6]. Thus, the optimum level of water absorption displayed in mortars with $15 \%$ replacement.
Based on Figure 6, the trend shows that as the curing duration increase, the water absorption rate decrease. According to the figure, the highest absorption reading shows in 7 days of curing period compared to 28 days and 60 days of curing for all stages of replacement. While the lowest water absorption shows in 60 days of curing. This is because the length of curing period gives a significant impact to the permeability, by extending the period of curing can reduce the permeability [4]. Thus, the permeability in 60 days of curing gives a decreasing in permeability in water absorption among the others because the length of curing period is longer than the others. Thus, among the three variations of curing period and the percentage of WGWP replaced, it is the best to described that $15 \%$ replacement of WGWP shows the optimum value of lowest water absorption.

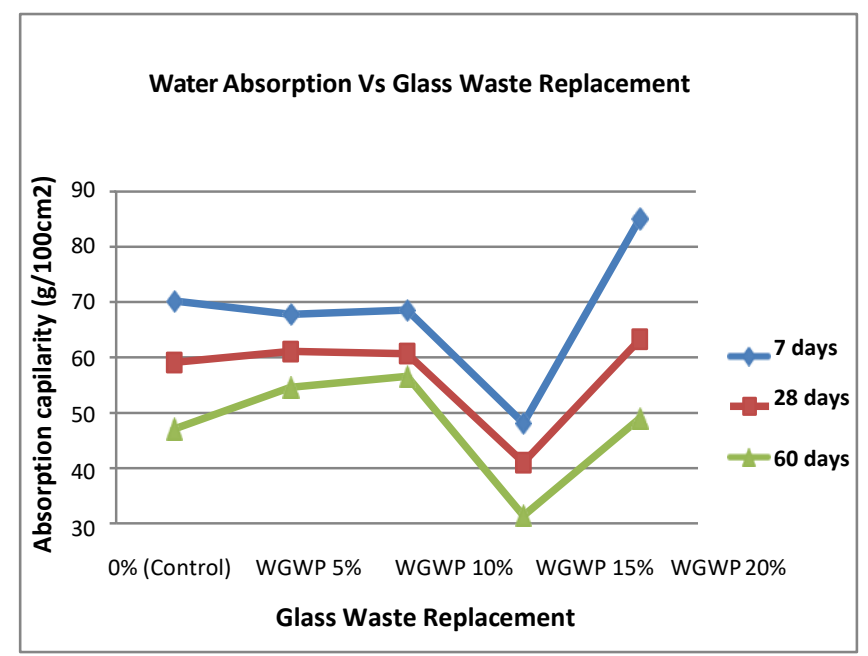

Fig 5 Water Absorption Vs Glass Waste Replacement

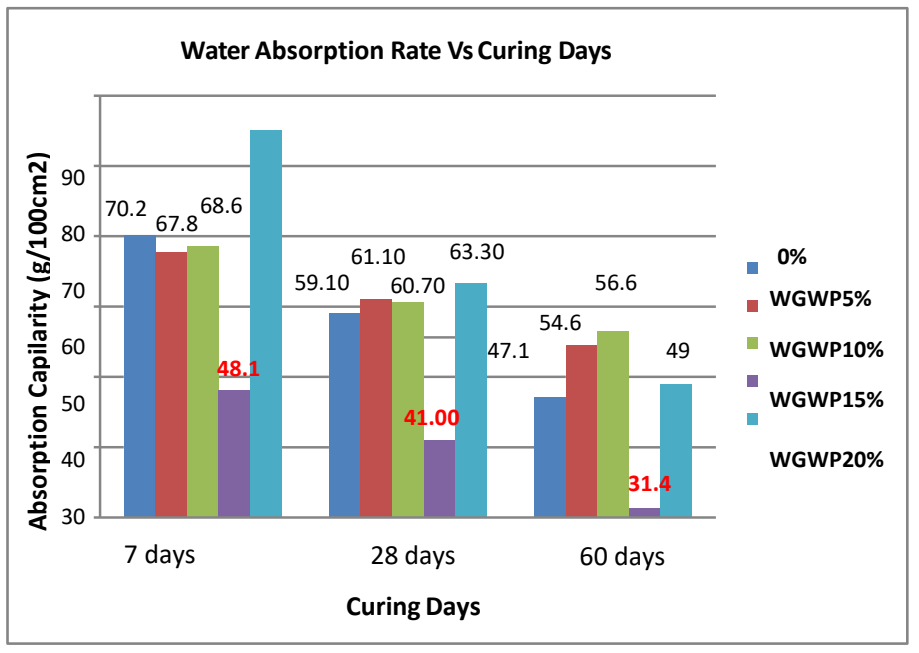

Fig 6 Water Absorption of cement WGWP mortar at 7, 28 and 60 days curing 


\section{CONCLUSION}

The surface area of WGWP was coarser than OPC and the density is lower than of OPC. The surface area increased as the particle size become small. Therefore, a small particle will react much quickly than a large particle. The XRD pattern indicates that WGWP is amorphous material which attributed to the glassy phase and from the chemical analysis shows that WGWP can be classified as Class $\mathrm{N}$ natural Pozzolanic. The effect on water absorption of mortar incorporated with windscreen glass powder showed that the increased in the replacement of WGWP up to $15 \%$ resulted in decreasing in the degree of water absorption due to decreases in water accessible. Prolong of period of curing 60 days gives a decreasing in the degree of water absorption.

\section{ACKNOWLEDGMENTS}

The authors would like to express their appreciation to Universiti Malaysia Terengganu (UMT) and Universiti Teknologi MARA for their assistance, cooperation and supports.

\section{REFERENCES}

[1] Ruth M, \& Dell'Anno P. 1997. An industrial ecology of the US glass industry. Resources policy 23:109124.

[2] Shayan A. 2002. Value-added utilization of waste glass in concrete. IABSE Symposium, Melbourne, page.1-11.

[3] Taha B., \& Nounu G. 2008. Properties of concrete contains mixed color waste recycled glass as sand and cement replacement. Construction and Building Materials 22:713-720.

[4] Nassar R., \& Soroushian P. 2012. Strength and durability of recycled aggregate concrete containing milled glass as partial replacement for cement. Construction Building Material, 29:368-377.

[5] Schwarz N, Cam H \& Neithalath N. (2008). Influence of a fine glass powder on the durability characteristics of concrete and its comparison to fly ash. Cement and Concrete Composites 30: 486-496

[6] Calmon, J. L., Sauer, A. S., Vieira, G. L., \& Teixeira, J. S. 2014. Effec of Windshield waste glass on the Properties of Structural Repair Mortars. Cement and Concrete Composites , 1-2.

[7] Idir, R., Cyr, M., \& Tagnit-Hamou, A. 2011. Potential pozzolanicity Glass Cullet Fines and Aggregates. Cement Concrete Compositions, 28-34.
[8] Pereira-de-Oliveira L.A. Castro-Gomes J.P., Santos M.S. 2012. The potential pozzolanic activity of glass and red-clay ceramic waste as cement mortars components. Construction and Building Materials 31:197-203.

[9] Kartini, K. M. 2010. Absorption and Permeability Performance of Selangor Rice Husk Ash Blended Grade 30 Concrete, 10.

[10]Malik, M. I. July. 2013. Study of Concrete Involving Use of Waste Glass as Partial Replacement of Fine Aggregate. Retrieved from IOSR Journal of Engineering (IOSRJEN): www.iosrjen.org

[11] American Society for Testing and Materials ASTM C1403-13. 2013. Standard Test Method for Rate of Water Absorption of Masonry Mortars.

[12] Du, H., \& Tan, K. H. 2014. Waste Glass Powder as Cement Replacement in Concrete. Journal of Advanced Concrete, 468-477.

[13] Kim J., Yi C., Zi G. 2015. Waste glass sludge as a partial cement replacement in mortar. Construction and Building Materials 75:242-246.

[14] Luiz C., Silva S., Lima V. Jamilla E., 2014. Effects of windshield waste glass on the properties of structural repair mortars". Cement and Concrete Composites 53:88-96.

[15]American Society for Testing And Materials ASTM-C618-12a. 2012 . Standard Specification for Coal Fly Ash and Raw or Calcined Natural Pozzolan for use in Concrete. 